\title{
The risks of warm nights and wet days in the context of climate change: assessing road safety outcomes in Boston, USA and Santo Domingo, Dominican Republic
}

\author{
José Ignacio Nazif-Munoz ${ }^{1,2,3^{*}}$ (D), Pablo Martínez ${ }^{1,2}$, Augusta Williams $^{3}$ and John Spengler ${ }^{3}$
}

\begin{abstract}
Background: There remains a dearth of cross-city comparisons on the impact of climate change through extreme temperature and precipitation events on road safety. We examined trends in traffic fatalities, injuries and property damage associated with high temperatures and heavy rains in Boston (USA) and Santo Domingo (Dominican Republic).

Methods: Official publicly available data on daily traffic outcomes and weather conditions during the warm season (May to September) were used for Boston (2002-2015) and Santo Domingo (2013-2017). Daily maximum temperatures and mean precipitations for each city were considered for classifying hot days, warm days, and warm nights, and wet, very wet, and extremely wet days. Time-series analyses were used to assess the relationship between temperature and precipitation and daily traffic outcomes, using a quasi-Poisson regression.

Results: In Santo Domingo, the presence of a warm night increased traffic fatalities with a rate ratio (RR) of 1.31 (95\% Cl [confidence interval]: 1.00,1.71). In Boston, precipitation factors (particularly, extremely wet days) were associated with increments in traffic injuries (RR 1.25, 95\% Cl: 1.18, 1.32) and property damages (RR 1.42, 95\% Cl: $1.33,1.51)$.

Conclusion: During the warm season, mixed associations between weather conditions and traffic outcomes were found across Santo Domingo and Boston. In Boston, increases in heavy precipitation events were associated with higher traffic injuries and property damage. As climate change-related heavy precipitation events are projected to increase in the USA, the associations found in this study should be of interest for road safety planning in a rapidly changing environment.
\end{abstract}

Keywords: Extreme weather conditions, Road safety, Boston and Santo Domingo, Time-series

\footnotetext{
* Correspondence: Jose.ignacio.nazif-munoz@usherbrooke.ca

'Faculté de médecine et des sciences de la santé, Université de Sherbrooke,

150, place Charles-Le Moyne, Lonqueuil, QC J4K OA8, Canada

${ }^{2}$ Centre de recherche Charles-Le Moyne - Saguenay - Lac-Saint-Jean, 150,

place Charles-Le Moyne, C. P. 200, Longueuil, Canadá

Full list of author information is available at the end of the article
}

C C The Author(s). 2021 Open Access This article is licensed under a Creative Commons Attribution 4.0 International License, which permits use, sharing, adaptation, distribution and reproduction in any medium or format, as long as you give appropriate credit to the original author(s) and the source, provide a link to the Creative Commons licence, and indicate if changes were made. The images or other third party material in this article are included in the article's Creative Commons licence, unless indicated otherwise in a credit line to the material. If material is not included in the article's Creative Commons licence and your intended use is not permitted by statutory regulation or exceeds the permitted use, you will need to obtain permission directly from the copyright holder. To view a copy of this licence, visit http://creativecommons.org/licenses/by/4.0/. The Creative Commons Public Domain Dedication waiver (http://creativecommons.org/publicdomain/zero/1.0/) applies to the data made available in this article, unless otherwise stated in a credit line to the data. 


\section{Highlights}

- This study made cross-city comparisons to analyze trends in road traffic outcomes associated with high temperatures and heavy rains.

- Increasingly heavy precipitation events were strongly and positively associated with traffic-related property damages and nonfatal injuries in the case of Boston.

- Modifying driving behavior through vehicle technology during heavy precipitation events should be paramount to avoid the potential for climate change-related human and economic losses.

- Road safety planning should address climate changerelated heavy precipitation events in the USA

\section{Background}

Our understanding of how road safety and climate change interact with each other is becoming utterly important. Road traffic injuries and deaths is a major public health concern. Current global estimates indicate that around 1.2 million people die each year from road crashes, and traffic injuries are the 7th leading cause of disability (Institute for Health Metrics and Evaluation (IHME), 2015). Consequently, road injuries and deaths have been recognized to be serious impediments to sustainable development across countries (Alam \& Mahal, 2016; World Health Organization, 2015; Prinja et al., 2015). Simultaneously, global warming has been recognized as one of the major challenges faced by humanity (Theofilatos \& Yannis, 2014a). In the coming decades, extreme weather events associated with global warming will test the sustainability, resilience, and flexibility of multiple systems, including road infrastructures and human capabilities (Theofilatos \& Yannis, 2014a; Mora et al., 2018). Under these new circumstances knowledge to lure out the multiple effects of climate change on road safety should be advanced. It is thus important to contrast how inclement weather may affect places with different levels of development of road infrastructures, transport policies, vehicles' technology, and/or health systems.

The association between road traffic collisions and weather has been systematically studied (Mora et al., 2018; Koetse \& Rietveld, 2009; Prati et al., 2018; Qiu \& Nixon, 2008; Theofilatos \& Yannis, 2014b; Razzaghi, 2019; Wang \& Zhang, 2017; Saha et al., 2016; Abdel-Aty et al., 2011; Malin et al., 2019; Otte im Kampe E et al., 2016; Parks et al., 2020), particularly with attention to winter conditions (e.g., rain, snow, and extreme cold temperatures). Increasing trends of crashes and nonfatal injuries during rainfall and snowfall have been consistently observed (Mora et al., 2018; Qiu \& Nixon, 2008; Abdel-Aty et al., 2011). Notably, rainfall following a dry period has been found to be remarkably dangerous (i.e., significant increment of traffic injuries and property damage) (Qiu \& Nixon, 2008). Findings might be explained by detrimental road conditions, malfunction of assistive vehicle technologies, impaired or inexperienced driving, and reduced enforcement under inclement weather, offset by less exposure and more conservative driving behavior during winter season (Mora et al., 2018; Koetse \& Rietveld, 2009; Prati et al., 2018; Qiu \& Nixon, 2008).

Latest studies have further suggested mixed associations between increases in global temperatures and injury and fatality rates (Malin et al., 2019; Otte im Kampe $E$ et al., 2016). In fact, the current rise in road death rates in the United States might be attributable to warming of the atmosphere (Parks et al., 2020; Robertson, 2018a; Robertson, 2018b). In a recent study (Wu et al., 2018) in continental United States, Wu and colleagues found that traffic fatalities and heat waves were associated with a 3,4\% overall increase. However, this effect was not homogenous since fatal crashes in rural areas were positively associated with heat waves by $6 \%$, but no effects were observed for high temperatures and traffic fatalities in urban areas. In another study in Hong Kong a positive but not significant association was found between road injuries under hot weather conditions. More specifically, hot weather was associated with an $11 \%$ increase in road injuries (Xing et al., 2019). Studies from other latitudes have pointed in similar directions (Mora et al., 2018; Ambo et al., 2020), however the effect of hot weather on road risk exposure may be parabolic. For instance, while in Australia people tend to cycle more the warmer the weather (Phung \& Rose, 2008), in Canada (Miranda-Moreno \& Nosal, 2011) and China (Zhan et al., 2020) at very high temperatures, individuals retreat from cycling and walking, thus decreasing exposure to road risks for cyclists and pedestrians. Other studies have considered during hot weather seasons the impact of rainfall on traffic fatalities and injuries. In Texas, Jackson and Sharif (Jacson and Sharif 2016) found no association between rainfall and traffic fatalities, and in Australia effects of these weather conditions were not observed in crash variation (Keay \& Simmonds, 2006). On the other hand, in Israel (Brodsky \& Hakkert, 1988) and Honk Kong (Xing et al., 2019) significant increases for road injuries were observed by magnitudes of 6 and $19 \%$ respectively.

Different pathways from extreme weather conditions to road traffic outcomes have been suggested. For instance, extreme hot weather may deteriorate road users' performance by increasing tiredness, inattention, or reckless crossing (Abdel-Aty et al., 2011; Böcker et al., 2013; Abedi \& Sadeghi-Bazargani, 2017). Additionally, warmer temperatures may be associated with not wearing or using substandard motorcycle personal protective devices (Abdel-Aty et al., 2011; Abedi \& Sadeghi- 
Bazargani, 2017; Malyshkina \& Mannering, 2009; Basagaña et al., 2015; Zhai et al., 2019; Craft et al., 2017; de Rome, 2019; Li et al., 2020; Maghsoudi et al., 2018). Further, constant exposure to heat, notably during hot seasons, may adversely affect vehicle conditions by incrementing tire pressure (Abdel-Aty et al., 2011; Parks et al., 2020; Abedi \& Sadeghi-Bazargani, 2017). Studies exploring the positive association between rain and road crashes suggest two pathways, loss of friction between tires and roads-making the brake system inefficient, and impaired visibility through either direct rain on the windshield or spray from other vehicles (Jaroszweski \& McNamara, 2014).

The impact of climate change through extreme temperature and precipitation events on the transportation system should be further explored to leverage the potential for public policies to prevent human losses due to vehicle collisions. Moreover, as the effects of extreme weather conditions on road traffic injuries and deaths may differ across latitudes, cross-country comparisons can aid to explore such variations across settings. In this study, we thus put our lens on two cities: Boston, MA (United States) and Santo Domingo (Dominican Republic). We have chosen these cities since they represent contrasting cases of road safety policy development. Boston has been selected because safety conditions for cyclists and pedestrians have vastly improved over time (Bongiorno et al., 2019). Boston is the United States' third most walkable and safest city for pedestrians (National Highway Traffic Safety Administration, 2017). Santo Domingo, on the other hand, cyclists and pedestrians have never been integrated into urban planning schemes (Nazif-Munoz et al., 2020) and as result it has one of the highest traffic fatality rates in the world (Lin, 2016). Ultimately, when road safety systems protect vulnerable road users more consistently, they are more likely to have a stronger road safety system, which protect all road users. We thus examine trends in road traffic fatalities associated with high temperatures and heavy rains using these cities independently, and then finish this work by assessing the extent under which the same weather conditions in Boston affect the number of traffic-crashes with injuries or property damage.

\section{Methods}

Daily meteorological conditions were available from the National Weather Service, for Boston (National Weather Service, 2020), and from the Oficina Nacional de Metereología, for Santo Domingo (Oficina Nacional de Meteorología (ONAMET), 2020). To reduce seasonal confounding, all analyses were confined to the warm season (May - September). In addition to the continuous value of daily maximum temperature (TMAX), minimum temperature (TMIN), and precipitation, binary variables were created at common thresholds. As Smith et al. (Smith et al., 2013) and Anderson et al. (Anderson \& Bell, 2011) concluded the operationalization of hot days affects the relationship between heat exposure and health. As such we opted for two metrics, hot days and warm days. As demonstrated by Kent at al. (Kent et al., 2014) Anderson et al. (Anderson \& Bell, 2011) these two measures could be good predictors for mortality. More specifically hot days were defined when TMAX $\geq 95$ th percentile of the TMAX for each city, and warm days when 85 th percentile $\leq$ TMAX $\leq 95$ th percentile. We also use warm nights when TMIN $\geq 95$ th percentile to explore the extent under which traffic outcomes were related to this condition. Indeed, crash response maybe different for daytime and nighttime (Keay \& Simmonds, 2006). For precipitation, wet days were considered days with any precipitation, very wet days were those with precipitation exceeding the warm-season daily mean precipitation, and extremely wet days were those with precipitation exceeding the daily mean precipitation of wet days.

Data on daily traffic fatalities and injuries that occurred in Boston, Massachusetts, were available from the Massachusetts Department of Transportation Interactive Mapping Portal for Analysis and Crash Tracking (IMPACT) for 2002-2015 (Department of Transportation Interactive Mapping Portal for Analysis and Crash Tracking, n.d.). Traffic fatalities for Santo Domingo were available from the Dominican Republic Ministry of Public Health for 2013-2017 (Ministerio de Salud Pública, Republica Dominicana, 2018). No personal data were used in this study and therefore ethics approval was not required.

Relative risk (RR) analyses (Williams et al., 2020) were used to determine each city's relative risk of traffic outcomes on a hot or wet day compared with days below thresholds set a priori. The RR quasi-Poisson regression model equation (Eq. 1) is as follows:

$$
\log \left(\mu_{j}\right)=\beta_{0}+\beta_{1} I_{j}[\text { HotDay }]
$$

Where $\mu_{j}$ is the expected number of traffic outcomes for each city on day $j$, and $I_{j}[$ HotDay $]$ is a binary indicator of a hot day. The same model was run substituting the indicator for hot day with the other temperature and precipitation indicators. To assess differences across RRs, we also calculated the ratio of relative risks (RRR) (Altman \& Bland, 2003).

Time-series (TS) analyses (Imai et al., 2015) were used to assess the relationship between temperature and precipitation and daily traffic fatalities per unit increase in temperature, using a quasi-Poisson regression. We use TS because it allows us to effectively account for timevarying factors such as temperature or precipitations in a series of traffic outcomes by simultaneously 
introducing functions of time to avoid any potential confounding produced by either season or long-term trends in the series (Imai et al., 2015). For this, we restricted the warm-season TS models using a non-parametric spline with 1 degree of freedom (df) per season to account for any long-term trends in traffic outcomes. To account for unobserved trends, a natural cubic spline with $2 \mathrm{df}$ for the continuous temperature or precipitation variable, determined a priori based on previous research (Wang, 1998), and to optimize the Generalized Cross Validation (GCV) criteria, was added. Day of the week was controlled for with indicator variables for each day, with reference to Friday. The TS model equation (Eq. 2) is as follows:

$$
\begin{aligned}
\log \left(\mu_{j}\right)= & \beta_{0}+s\left(\beta_{1 j}\left(T_{\text {MAX }}\right)\right)+\beta_{2} I_{j}[\text { HotDay }] \\
& +\beta_{3} I_{j}(\text { Day of Week }) \\
& +s\left(\beta_{4 j}(\text { Date })\right)
\end{aligned}
$$

where $\mu_{j}$ is the expected number of traffic outcome for each city on day $j, I_{j}[$ HotDay $]$ is a binary indicator of a hot day, $I_{j}[$ Day of Week] is an indicator for day of week, $s$ represents splines on variables with non-linear trends. The same model was run substituting temperature variables for precipitation variables and for each city of interest.

\section{Results}

\section{Fatal collisions in Boston, MA}

There was a daily average of 0.07 traffic fatalities per day during the warm season in Boston, MA from 2002 to 2015 , and an average of 1.5 traffic fatalities per year 100, 000 population, which corresponds to a total of 146 traffic fatalities during this period (Table 1). When evaluating the RRs of traffic fatalities in Boston, MA, there were no precipitation or temperature factors significantly associated with fatalities during the warm season (Table 2). An interesting association however is between traffic fatalities and warm night with an $\mathrm{RR}=1.08$, (95\% confidence interval $[\mathrm{CI}]: 0.97,1.20)$.

\section{Fatal collisions in Santo Domingo, RD}

In Santo Domingo, there were 1.53 traffic fatalities per day on average during the warm season, and an average of 14.1 traffic fatalities per year 100,000 population, which corresponds to a total of 1404 fatalities from 2013 to 2017 (Table 3). Similar to Boston the presence of a warm night (TMIN $\leq 95$ th percentile) preceding fatal traffic incidents was associated with an $\mathrm{RR}=1.31$ (95\% CI: 1.00, 1.71) (Table 4), and the other variables did not capture significant variation for this outcome.
Table 1 Descriptive statistics of traffic fatalities, meteorological conditions for Boston, MA (2002-2015) during the warm season. $\mathrm{p}$ indicates percentile

\begin{tabular}{ll}
\hline & Boston, MA \\
\hline Total Fatalities & 146 \\
Daily Mean Fatalities & 0.07 \\
Daily Max Temperature $\left[{ }^{\circ} \mathrm{C}\right]$ & 24.33 \\
Daily Min Temperature $\left[{ }^{\circ} \mathrm{C}\right]$ & 15.69 \\
Total Hot Days $\left(\mathrm{T}_{\text {MAX }} \geq 95\right.$ thp $^{\text {th }}$ & 115 \\
Total Warm Days $\left(85^{\text {th }} \mathrm{p} \leq \mathrm{T}_{\text {MAX }} \leq 95^{\text {th }} \mathrm{p}\right)$ & 300 \\
Total Warm Nights $\left(\mathrm{T}_{\text {MIN }} \leq 95^{\text {th }} \mathrm{p}\right)$ & 119 \\
Mean Daily Precipitation (all days) $[\mathrm{mm}]$ & 3.05 \\
Mean Daily Precipitation (days with any rain) $[\mathrm{mm}]$ & 9.04 \\
Total Wet Days $(>0$ mm) & 707 \\
Total Very Wet Days $(>$ mean) & 419 \\
Total Extremely Wet Days (>mean of rainy days) & 236 \\
Population & 685,094 \\
\hline
\end{tabular}

Time series analyses of Boston, MA USA and Santo Domingo, RD

The estimated effects of maximum temperature at nights were nonlinear for traffic fatalities in both cities. In Boston, higher RR of traffic fatalities at hot temperatures are observed. However at average temperatures, traffic fatalities are stable, and then decline at lower temperatures (Figure S1 in Supplementary Material). In Santo Domingo, on the other hand, the response curve suggests increases of RRs in traffic fatalities at average temperatures, whereas extreme temperatures tend to have wide confidence intervals and lower RRs (Figure S2 in Supplementary Material).

\section{Non-fatal injury and property damage collisions in Boston, MA, USA}

For Boston, data were also available on traffic collisions that resulted in non-fatal injuries and property damage. During this study period, there were 25,275 collisions resulting in non-fatal injury and 40,936 in property

Table 2 Relative risk (RR) with 95\% confidence interval (CI) of

\begin{tabular}{|c|c|c|}
\hline \multirow[t]{2}{*}{ Condition } & \multicolumn{2}{|c|}{ Boston, MA } \\
\hline & RR & $95 \% \mathrm{Cl}$ \\
\hline Hot Days $\left(T_{\text {MAX }} 95^{\text {th }} \mathrm{p}\right)$ & 0.95 & $(0.84,1.06)$ \\
\hline Warm Days $\left(85^{\text {th }} p \leq T_{\text {MAX }} \quad 95^{\text {th }} p\right)$ & 1.09 & $(0.90,1.13)$ \\
\hline Warm Nights $\left(T_{\text {MIN }} \leq 95^{\text {th }} p\right)$ & 1.08 & $(0.97,1.20)$ \\
\hline Wet Days (>0 mm) & 1.01 & $(0.93,1.09)$ \\
\hline Very Wet Days (>mean) & 0.99 & $(0.90,1.09)$ \\
\hline Extremely Wet Days (>mean of rainy days) & 0.95 & $(0.83,1.08)$ \\
\hline
\end{tabular}
traffic fatalities on warm-season days with extreme heat or precipitation for Boston, MA

$\mathrm{p}$ indicates percentile 
damage. When analyzing these data, we observe four groups of findings (Table 5). First, except for hot days and traffic injuries in which a non-significant increase of 9\% (RR: 1.09 95\% CI: 0.99, 1.21) was observed, warm days do not capture concomitant variation in non-fatal injuries nor property damage. Second, warm nights suggest decreases by 13\% (RR: 0.87 95\% CI: 0.78, 0.98) in non-fatal injury rates, and by $9 \%$ (RR: $0.9195 \%$ CI: 0.82 , $1.01)$ in property damage rates. Third, all the precipitation thresholds considered resulted in significantly greater RR of non-fatal injury collisions and property damage. Further, increases in wet conditions are associated with higher RRs of property damage. For instance, the RR of collisions resulting in property damage on wet days is 1.25 (95\% CI: $1.19,1.31)$, whereas for this outcome on extremely wet days the RR is 1.42 (95\% CI: $1.33,1.51)$. The ratio of RR (RRR) for these two RRs is 1.05 (95\% CI: 1.02, 1.10), suggesting significant higher risks of collisions resulting in property damage on extremely wet days relative to wet days.

Lastly, when comparing the risks of collisions resulting in non-fatal injuries (RR: 1.25 95\% CI: 1.16, 1.34) and property damages (RR: $1.4295 \%$ CI: $1.33,1.51$ ) with the risk for traffic fatalities (RR: $0.9595 \%$ CI: $0.83,1.08$ ) on extremely wet days, we obtain the following RRRs: for non-fatal injuries 1.12 (95\% CI:1.06, 1.19) and for property damage 1.19 (95\% CI:1.11, 1.27). These comparisons suggest that on very wet days, non-fatal injuries and property damage have a 12 and 19\% higher association with weather conditions than does traffic fatalities.

\section{Discussion}

Understanding how traffic crashes are distributed in consideration to extreme weather events related to climate change requires the development of studies which contrast dissimilar territories (Bergel-Hayat et al., 2013). For this, our study analyzed Boston and Santo Domingo independently. While there were some interesting signals between variables, we did not find however that overall extreme weather conditions associated with heat or rain were consistently capturing concomitant variation on traffic fatality rates in both cities. Nevertheless, when analyses were extended to road injuries and property damages in Boston, our findings suggest a series of complex associations. While variables operationalizing high temperatures at different times signaled mild decreases in non-fatal injuries and property damages, different thresholds to wet days, however, strongly indicated increases in these two outcomes.

To understand findings related to fatal and non-fatal crashes, we need to identify both different road risks' (temperatures, rain, number of trips) exposure levels (frequency or intensity), and second, a combination of these road risks (Hakkert et al., 2002). First, lack of variation in the fatal outcomes is consistent with previous studies which have stratified analyses by rural and urban settings (Xing et al., 2019). While Wu et al. found that traffic fatalities increased by $3.4 \%$ at the presence of heat waves in the United States, in their study this association was null for urban settings. In our study, while the null statistical significance of the effects across Boston and Santo Domingo was similar, the sign and magnitude of these results, however, prevents us from suggesting the presence of unique pathways between high temperatures and traffic fatalities in highly contrasting cities. We can only suggest for Boston that increases in temperatures may be associated with decreasing in the number of road trips as property damage in Boston may have decreased-albeit not significantly. In short, if very high temperatures are present, road users in this city may avoid ground travelling, which in turn reduces the chances of experiencing road crashes and fatal ones (Otte im Kampe E et al., 2016). However, this null finding may also indicate that if high temperatures do not necessarily affect the number of trips, drivers may be mitigating its adverse effects on driving performance (i.e., increase of tiredness, or inattention (Abdel-Aty et al., 2011; Xing et al., 2019; Böcker et al., 2013; Abedi \& Sadeghi-Bazargani, 2017)) by using vehicles' air conditioners or opening vehicles' windows. For instance, the mitigating effects of air conditioners in households on negative health outcomes has been documented in United States and China (Ostro et al., 2010; Ma et al., 2014). While part of this explanation could be applied to Boston since studies have suggested significant increases in vehicles' air conditioners during warm seasons (Gately et al., 2017), it is also important to acknowledge that people living in warmer areas, as Santo Domingo, tend to adapt to hot temperatures (Lian et al., 2020; Bobb et al., 2014), and therefore effects of high temperatures on driving performance may not be as acute. When health and fire services attend to collisions on time, the probability of traffic deaths decreases (Sánchez-Mangas et al., 2010). Since in Boston increasing of high temperatures has been associated with raises in police, health services and fire services dispatches (Williams et al., 2020), then it is possible that Boston's emergency medical services have provided prompt attention to severe car crashes to the point of successfully decreasing traffic fatalities. This interpretation is reinforced with our result of hot days associated with increases in injuries by $9 \%$ (95\% CI: -1.0 , 21.0) (which is consistent with a non-significant increase also found in Hong Kong of $11 \%$ (95\% CI: - 4.0, 30.0) in this association). While high temperatures may deteriorate road users' performance by increasing tiredness or inattention, which in turn leads to an augmentation of road injuries, the timely attention from medical services 
Table 3 Descriptive statistics of traffic fatalities, meteorological conditions for Santo Domingo, DR (2013-2017) during the warm season. $p$ indicates percentile

\begin{tabular}{|c|c|}
\hline & Santo Domingo, DR \\
\hline Total Fatalities & 1404 \\
\hline Daily Mean Fatalities & 1.53 \\
\hline Daily Max Temperature $\left[{ }^{\circ} \mathrm{C}\right]$ & 32.24 \\
\hline Daily Min Temperature $\left[{ }^{\circ} \mathrm{C}\right]$ & 24.83 \\
\hline Total Hot Days $\left(T_{\text {MAX }} \geq 95^{\text {th }} p\right)$ & 66 \\
\hline Total Warm Days $\left(85^{\text {th }} p \leq T_{\text {MAX }} \leq 95^{\text {th }} p\right)$ & 104 \\
\hline Total Warm Nights $\left(T_{\text {MIN }} \leq 95^{\text {th }} p\right)$ & 55 \\
\hline Mean Daily Precipitation (all days) $[\mathrm{mm}]$ & 5.56 \\
\hline Mean Daily Precipitation (days with any rain) $[\mathrm{mm}]$ & 12.21 \\
\hline Total Wet Days (>0 mm) & 481 \\
\hline Total Very Wet Days (>mean) & 302 \\
\hline Total Extremely Wet Days (>mean of rainy days) & 218 \\
\hline Population & $3,318,000$ \\
\hline
\end{tabular}

may be indeed reducing the risk of fatalities for these crash victims. Last, another element derived from these results is the analogous association between warm nights and traffic fatalities. In our study this association was positive and non-significant for both cities albeit much higher for Santo Domingo with a 31\% (95\% CI: 0.0, 71.0) increase. In Wu et al.'s study this association was also non-significant and positive with a $7.1 \%$ increase $(95 \%$ CI: - 1.2-16.1) which is highly similar to our results from Boston, where we observed an $8.0 \%$ increase (95\% CI: 3.0, 20.0). Further, studies have suggested that this association can be explained by the prevalence of risk driving behavior such as driving under the influence of alcohol which is correlated with this type of weather condition (Xing et al., 2019). In the Dominican Republic, various studies have indicated that alcohol consumption increases the risk of traffic injuries by more than 3 times at the national level (Shinar, 2012, Cherpitel et al. 2021) and by more than 4 times in Santo Domingo (Borges et al., 2017).

Table 4 Relative risk (RR) with 95\% confidence interval (Cl) of traffic fatalities on warm-season days with extreme heat or precipitation for Santo Domingo, DR

\begin{tabular}{|c|c|c|}
\hline \multirow[t]{2}{*}{ Condition } & \multicolumn{2}{|c|}{ Santo Domingo, DR } \\
\hline & RR & $95 \% \mathrm{Cl}$ \\
\hline Hot Days $\left(T_{\text {MAX }} 95^{\text {th }} \mathrm{p}\right)$ & 1.08 & $(0.82,1.41)$ \\
\hline Warm Days $\left(85^{\text {th }} p \leq T_{\text {MAX }} \quad 95^{\text {th }} p\right)$ & 1.09 & $(0.87,1.35)$ \\
\hline Warm Nights $\left(T_{\text {MIN }} \leq 95^{\text {th }} p\right)$ & 1.31 & $(1.00,1.71)$ \\
\hline Wet Days (>0 mm) & 0.88 & $(0.76,1.03)$ \\
\hline Very Wet Days (>mean) & 0.95 & $(0.79,1.15)$ \\
\hline Extremely Wet Days (>mean of rainy days) & 1.06 & $(0.84,1.32)$ \\
\hline
\end{tabular}

$\mathrm{p}$ indicates percentile
Second, the presence of wet days being associated with higher increases of road injuries and property damage relative to traffic fatalities, as our findings of RRRs indicate, suggests three interrelated hypotheses. First, other studies have noticed that increments in rains are linked with falls in the severity of crashes (from fatal, to injury, to property damage) (Doherty et al., 1993; Eisenberg, 2004). Indeed, Edwards (Edwards, 1999) proposed that under inclement wet weather conditions drivers tend to significantly reduce vehicles' speed, which in turn decreases the impact of a collision but not necessarily the proportion of collisions. A similar finding was also identified by Wu et al. (Wu et al., 2018) in which road traffic fatalities were consistently decreasing the higher the precipitations were observed in continental United States. Our results however are consistent with those of Xing et al. (Xing et al., 2019) in which road injuries are analyzed. In Hong Kong, an increase of 34.0\% (95\% CI: 16.0-55.0) in road injuries were observed after the presence of heavy precipitation, in our study in Boston, our variable extreme wet days was associated with an increase of $19.0 \%$ (95\% CI: $16.0-34.0$ ) in this outcome. Complementary to this hypothesis, the increase of road injuries and property damage can also be explained by how vehicles' brake systems become inefficient under slippery roads. Indeed, tires lose traction to roads when the presence of water mixed with oil is prevalent (Eisenberg, 2004). Last, water also impairs drivers' visibility through either direct rain on the windshield or spray from other vehicles (Jaroszweski \& McNamara, 2014).

The pattern found for Boston, where increases in precipitation were associated with higher traffic injuries and property damage, are indeed of particular interest for road safety planning in the USA. The Fourth National 
Table 5 Relative risk (RR) with 95\% confidence interval (Cl) of traffic collisions resulting in non-fatal injury or property damage on warm-season days with extreme heat or precipitation in Boston, MA

\begin{tabular}{|c|c|c|c|c|}
\hline \multirow[t]{2}{*}{ Condition } & \multirow{2}{*}{$\begin{array}{l}\text { Non-Fatal Injury } \\
\text { RR }\end{array}$} & \multicolumn{3}{|c|}{ Property Damage } \\
\hline & & $95 \% \mathrm{Cl}$ & RR & $95 \% \mathrm{Cl}$ \\
\hline Hot Days $\left(T_{\text {MAX }} \geq 95^{\text {th }} p\right)$ & 1.09 & $(0.99,1.21)$ & 0.96 & $(0.86,1.07)$ \\
\hline Warm Days $\left(85^{\text {th }} p \leq T_{\text {MAX }} \leq 95^{\text {th }} p\right)$ & 0.98 & $(0.91,1.05)$ & 0.94 & $(0.88,1.01)$ \\
\hline Warm Nights $\left(T_{\text {MIN }} \leq 95^{\text {th }} p\right)$ & 0.87 & $(0.78,0.98)$ & 0.91 & $(0.82,1.01)$ \\
\hline Wet Days (>0 mm) & 1.19 & $(1.13,1.25)$ & 1.25 & $(1.19,1.31)$ \\
\hline Very Wet Days (>mean) & 1.27 & $(1.19,1.34)$ & 1.36 & $(1.29,1.43)$ \\
\hline Extremely Wet Days (>mean of rainy days) & 1.25 & $(1.16,1.34)$ & 1.42 & $(1.33,1.51)$ \\
\hline
\end{tabular}

Bold indicates RRs for which the $95 \% \mathrm{Cl}$ exclude the null $(\mathrm{RR}=1.0)$, and $\mathrm{p}$ indicates percentile

Climate Assessment (NCA4) (U.S. Global Change Research Program, 2018), completed in November 2018, stated that heavy precipitation events linked to climate change are expected to increase during the twenty-first century, particularly affecting Northeastern United States. Thus, as extremely wet days will become more common, their incidence on number of traffic injuries and property damage should be more carefully considered.

Our evaluation of the general association of extreme weather conditions during warm seasons has the following limitations. First, our exposure variable is measuring daily averages of temperatures and precipitations. Variation in these two variables could be however better captured by having access to hourly information. This would allow us to identify a more precise correspondence between extreme weather conditions and the time when collisions occurred. Nevertheless, since we were limited to daily information for our exposure variables, we could only use day as unit of analysis. Second, traffic outcomes were not broken-down according to drivers, cyclists, pedestrians, sex, or age groups. Recent studies have suggested that males relatively to females are more likely to be affected by heat waves as well as individuals aged 46-65 are also more likely to be affected by these weather conditions (Xing et al., 2019). It is possible thus that our results are masking important differences between these demographics. In terms of road users, effects of temperature increases may be, relative to motor vehicle drivers, more detrimental in cyclists. Third, as it is common in this literature, the examination of enforcement variables remains an important challenge. The effects of the weather could indeed be mediated by the type and quantity of emergency services responses during these conditions. Fourth, our estimates may be confounded by other unmeasured time-varying variables such as decreases in helmet use in Santo Domingo or increases in safety motor vehicle requirements in Boston. In this regard it is important to highlight that while our initial effort was to attempt to find similarities to understand pathways between two highly contrasting cities, cross-city comparisons should adjust for other time varying factors linked to road safety capacity more precisely. Last, and relatedly to our fourth limitation, to have more adequate cross-city comparisons analysis should consider matching periods of analysis. In our case Boston considered the 2002-2015 period whereas Santo Domingo a shorter one with 2013-2017.

\section{Conclusions}

What type of policies and follow up studies could be explored from these findings and their related hypotheses? An appropriate intervention would be to test weather drivers, cyclist and pedestrian behaviors could be modified during adverse weather conditions through devices such as vehicle's dashboards, mobile phone alerts and portable road signs. For this, studies on mobile applications and vehicle's dashboards should be designed considering how the sudden provision of warning information must necessarily offset driver and pedestrian distraction. Analyses of portable road signs should for instance consider which type of messages in form and content are effective to immediately reduce speed. Depending on how traffic rules are designed and enforced in specific administrative units, immediate and provisional legal reduction of speed limits under extreme wet weather, and road quality maintenance and improvement with attention to mitigation of slippery conditions should also be studied. Regarding the presence of hot temperatures, studies should consider more carefully the use of air conditioners and how these indeed contribute to road safety. It is important to acknowledge however that excessive and malfunctioning use of air conditioners in vehicles has been associated with increment of external and car cabins air pollution (Gately et al., 2017; Gołofit-Szymczak et al., 2019). Second, analyses of temperature effects on road outcomes with attention to emergency dispatches should be explicitly carried out. This would provide a better understanding of how potential overcrowding of emergency systems during extreme weather conditions maybe or not affecting medical responses. 


\section{Supplementary Information}

The online version contains supplementary material available at https://doi. org/10.1186/s40621-021-00342-w.

\section{Additional file 1:}

\section{Acknowledgements}

Not applicable.

\section{Authors' contributions}

JINM and AW design the study and collected data, JINM, PM and JS carried out literature review, AW carried out the analysis, JINM wrote the first draft, all authors contribute to revisions and final writing of the manuscript. The author(s) read and approved the final manuscript.

\section{Funding}

This research was founded by the Fonds de recherche du Québec - Santé Programme Chercheurs-boursiers - Junior 1.

\section{Availability of data and materials}

Not applicable.

\section{Declarations}

Ethics approval and consent to participate

Not applicable.

\section{Consent for publication}

Not applicable.

\section{Competing interests}

None.

\section{Author details}

${ }^{1}$ Faculté de médecine et des sciences de la santé, Université de Sherbrooke, 150, place Charles-Le Moyne, Longueuil, QC J4K 0A8, Canada. ${ }^{2}$ Centre de recherche Charles-Le Moyne - Saguenay - Lac-Saint-Jean, 150, place Charles-Le Moyne, C. P. 200, Longueuil, Canadá. ${ }^{3}$ Department of Environmental Health, Harvard T.H. Chan School of Public Health, 401 Park Drive, 4th Floor West, 404N, Boston, MA 02215, USA.

Received: 31 March 2021 Accepted: 27 June 2021 Published online: 19 July 2021

\section{References}

Abdel-Aty M, Ekram AA, Huang H, Choi K. A study on crashes related to visibility obstruction due to fog and smoke. Accid Anal Prev. 2011;43(5):1730-7. https://doi.org/10.1016/j.aap.2011.04.003.

Abedi L, Sadeghi-Bazargani H. Epidemiological patterns and risk factors of motorcycle injuries in Iran and eastern Mediterranean region countries: a systematic review. Int J Inj Control Saf Promot. 2017;24(2):263-70. https://doi. org/10.1080/17457300.2015.1080729.

Alam K, Mahal A. The economic burden of road traffic injuries on households in South Asia. PLoS One. 2016;11(10):e0164362. https://doi.org/10.1371/journal. pone.0164362.

Altman DG, Bland JM. Interaction revisited: the difference between two estimates. Bmj. 2003;326(7382):219. https://doi.org/10.1136/bmj.326.7382.219.

Ambo TB, Ma J, Fu C. "Investigating influence factors of traffic violation using multinomial logit method." International journal of injury control and safety promotion. 2020;28.1:78-85.

Anderson GB, Bell ML. Heat waves in the United States: mortality risk during heat waves and effect modification by heat wave characteristics in 43 US communities. Environ Health Perspect. 2011:119(2):210-8. https://doi.org/1 0.1289/ehp.1002313.

Basagaña X, Escalera-Antezana Juan P, Dadvand P, Llatje Ò, Barrera-Gómez J Cunillera J, et al. High ambient temperatures and risk of motor vehicle crashes in Catalonia, Spain (2000-2011): a time-series analysis. Environ Health Perspect. 2015;123(12):1309-16. https://doi.org/10.1289/ehp.1409223.
Bergel-Hayat R, Debbarh M, Antoniou C, Yannis G. Explaining the road accident risk: weather effects. Accid Anal Prev. 2013;60:456-65. https://doi.org/10.1016/ j.aap.2013.03.006

Bobb JF, Peng RD, Bell ML, Dominici F. Heat-related mortality and adaptation to heat in the United States. Environ Health Perspect. 2014;122(8):811-6. https:// doi.org/10.1289/ehp.1307392.

Böcker L, Dijst M, Prillwitz J. Impact of everyday weather on individual daily travel Behaviours in perspective: a literature review. Transp Rev. 2013;33(1):71-91. https://doi.org/10.1080/01441647.2012.747114.

Bongiorno C, et al. Comparing bicycling and pedestrian mobility: Patterns of non-motorized human mobility in Greater Boston. J Transport Geography. 2019;80:102501.

Borges G, Monteiro M, Cherpitel CJ, Orozco R, Ye Y, Poznyak V, et al. Alcohol and road traffic injuries in Latin America and the Caribbean: a case-crossover study. Alcohol Clin Exp Res. 2017:41(10):1731-7. https://doi.org/10.1111/a cer.13467.

Brodsky H, Hakkert AS. Risk of a road accident in rainy weather. Accid Anal Prev. 1988;20(3):161-76. https://doi.org/10.1016/0001-4575(88)90001-2.

Cherpitel CJ, Witbrodt J, Ye Y, Monteiro MG, Málaga H, Báez J, et al. Road traffic injuries and substance use among emergency department patients in the Dominican Republic and Peru. Revista panamericana de salud publica. 2021; $45: e 31$

Craft G, Van Bui T, Sidik M, Moore D, Ederer DJ, Parker EM, et al. A comprehensive approach to motorcycle-related head injury prevention: experiences from the field in Vietnam, Cambodia, and Uganda. International journal of environmental research and public health, 2017;14(12):1486.

de Rome L. Could wearing motorcycle protective clothing compromise rider safety in hot weather? Accid Anal Prev. 2019;128:240-7. https://doi.org/10.1 016/j.aap.2019.04.011

Department of Transportation Interactive Mapping Portal for Analysis and Crash Tracking (n.d.). https://www.mma.org/massdot-launches-web-portal-for-crashdata/

Doherty ST, Andrey JC, Marquis JC. Driver adjustments to wet weather hazards. Climatological Bull. 1993;27(3):154-64.

Edwards JB. Speed adjustment of motorway commuter traffic to inclement weather. Transport Res F: Traffic Psychol Behav. 1999;2(1):1-14. https://doi. org/10.1016/S1369-8478(99)00003-0.

Eisenberg D. The mixed effects of precipitation on traffic crashes. Accid Anal Prev. 2004;36(4):637-47. https://doi.org/10.1016/S0001-4575(03)00085-X

Gately CK, Hutyra LR, Peterson S, Wing IS. Urban emissions hotspots: quantifying vehicle congestion and air pollution using mobile phone GPS data. Environ Pollut. 2017;229:496-504. https://doi.org/10.1016/j.envpol.2017.05.091.

Gołofit-Szymczak M, Stobnicka-Kupiec A, Górny RL. Impact of air-conditioning system disinfection on microbial contamination of passenger cars. Air Quality, Atmosphere \& Health. 2019;12(9):1127-35. https://doi.org/10.1007/ s11869-019-00731-7.

Hakkert, A. Shalom, L. Braimaister, and I. Van Schagen. The uses of exposure and risk in road safety studies. Vol. 2002, no. 12. SWOV Institute for Road Safety, 2002.

Imai C, Armstrong B, Chalabi Z, Mangtani P, Hashizume M. Time series regression model for infectious disease and weather. Environ Res. 2015:142:319-27. https://doi.org/10.1016/j.envres.2015.06.040

Institute for Health Metrics and Evaluation (IHME). GBD Compare. Seattle: IHME, University of Washington; 2015.

Jackson TL, Sharif HO. Rainfall impacts on traffic safety: rain-related fatal crashes in Texas. Geomatics Natural Hazards Risk. 2016;7(2):843-60. https://doi.org/1 $0.1080 / 19475705.2014 .984246$

Jaroszweski D, McNamara T. The influence of rainfall on road accidents in urban areas: a weather radar approach. Travel Behav Soc. 2014;1(1):15-21. https:// doi.org/10.1016/j.tbs.2013.10.005

Keay K, Simmonds I. Road accidents and rainfall in a large Australian city. Accid Anal Prev. 2006;38(3):445-54. https://doi.org/10.1016/j.aap.2005.06.025.

Kent ST, McClure LA, Zaitchik BF, Smith TT, Gohlke JM. Heat waves and health outcomes in Alabama (USA): the importance of heat wave definition. Environ Health Perspect. 2014;122(2):151-8. https://doi.org/10.1289/ehp.1307262.

Koetse MJ, Rietveld P. The impact of climate change and weather on transport: an overview of empirical findings. Transp Res Part D: Transp Environ. 2009; 14(3):205-21. https://doi.org/10.1016/j.trd.2008.12.004

Li Q, Adetunji O, Pham CV, Tran NT, Chan E, Bachani AM. Helmet use among motorcycle riders in $\mathrm{Ho}$ Chi Minh City, Vietnam: results of a five- 
year repeated cross-sectional study. Accident Analysis Prev. 2020;144: 105642.

Lian T, Fu Y, Sun M, Yin M, Zhang Y, Huang L, et al. Effect of temperature on accidental human mortality: a time-series analysis in Shenzhen, Guangdong Province in China. Sci Rep. 2020;10(1):1-10.

Lin Y-C. The global distribution of the burden of road traffic injuries: evolution and intra-distribution mobility. J Transp Geogr. 2016;56:77-91. https://doi. org/10.1016/j.jtrangeo.2016.09.002.

Ma W, Chen R, Kan H. Temperature-related mortality in 17 large Chinese cities: how heat and cold affect mortality in China. Environ Res. 2014;134:127-33. https://doi.org/10.1016/j.envres.2014.07.007.

Maghsoudi A, Boostani D, Rafeiee M. Investigation of the reasons for not using helmet among motorcyclists in Kerman, Iran. Int J Inj Control Saf Promot. 2018;25(1):58-64. https://doi.org/10.1080/17457300.2017.1323931.

Malin F, Norros I, Innamaa S. Accident risk of road and weather conditions on different road types. Accid Anal Prev. 2019;122:181-8. https://doi.org/10.1016/ j.aap.2018.10.014.

Malyshkina NV, Mannering FL. Markov switching multinomial logit model: an application to accident-injury severities. Accid Anal Prev. 2009;41(4):829-38. https://doi.org/10.1016/j.aap.2009.04.006.

Ministerio de Salud Pública, Republica Dominicana. Demografía y Fatalidades. Santo Domingo, República Dominicana (2018).

Miranda-Moreno L, Nosal T. Weather or not to cycle: temporal trends and impact of weather on cycling in an urban environment. Transport Res Record. 2011; 2247(1):42-52. https://doi.org/10.3141/2247-06.

Mora C, Spirandelli D, Franklin EC, Lynham J, Kantar MB, Miles W, et al. Broad threat to humanity from cumulative climate hazards intensified by greenhouse gas emissions. Nat Clim Chang. 2018;8(12):1062-71. https://doi. org/10.1038/s41558-018-0315-6.

National Highway Traffic Safety Administration. Traffic Safety Facts. Pedestrians. 2017. https://crashstats.nhtsa.dot.gov/Api/Public/NiewPublication/812681

National Weather Service. Watch/warning/advisory criteria. Available at: https:// www.weather.gov/box/criteria. Accessed 13 Feb 2020.

Nazif-Munoz Jl, Puello A, Williams A, Nandi A. Can a new emergency response system reduce traffic fatalities? The case of the 911-emergency response system in the Dominican Republic. Accid Anal Prev. 2020;143:105513. https:// doi.org/10.1016/j.aap.2020.105513.

Oficina Nacional de Meteorología (ONAMET). Informe del tiempo. 2020. https:// www.onamet.gob.do/index.php/pronosticos/informe-del-tiempo. Accessed 21 Oct 2020

Ostro B, Rauch S, Green R, Malig B, Basu R. The effects of temperature and use of air conditioning on hospitalizations. Am J Epidemiol. 2010;172(9):1053-61. https://doi.org/10.1093/aje/kwq231.

Otte im Kampe E, Kovats S, Hajat S. Impact of high ambient temperature on unintentional injuries in high-income countries: a narrative systematic literature review. BMJ Open. 2016;6(2):e010399.

Parks RM, Bennett JE, Tamura-Wicks H, Kontis V, Toumi R, Danaei G, et al. Anomalously warm temperatures are associated with increased injury deaths. Nat Med. 2020;26(1):65-70. https://doi.org/10.1038/s41591-019-0721-y.

Phung J, Rose G. Temporal variations in Melbourne's bike paths. In: Proceedings of 30th Australasian Transport Research Forum, Melbourne: Forum papers, 25-27 September 2007, Melbourne, Victoria, Australia, CD-ROM; 2008.

Prati G, Marín Puchades V, De Angelis M, Fraboni F, Pietrantoni L. Factors contributing to bicycle-motorised vehicle collisions: a systematic literature review. Transp Rev. 2018;38(2):184-208. https://doi.org/10.1080/01441647.201 7.1314391.

Prinja S, Jagnoor J, Chauhan AS, Aggarwal S, Ivers R. Estimation of the economic burden of injury in north India: a prospective cohort study. Lancet. 2015; 385(Suppl 2):S57.

Qiu L, Nixon WA. Effects of adverse weather on traffic crashes: systematic review and meta-analysis. Transp Res Rec. 2008;2055(1):139-46. https://doi.org/1 0.3141/2055-16

Razzaghi, Alireza, et al. "Risk factors of deaths related to road traffic crashes in World Health Organization regions: A systematic review." Archiv Trauma Res, $8,2,2019,57$

Robertson L. Climate change, weather and road deaths. Injury Prev. 2018a;24(3): 232-5. https://doi.org/10.1136/injuryprev-2017-042419.

Robertson LS. Reversal of the road death trend in the U.S. in 2015-2016: An examination of the climate and economic hypotheses. J Transport Health. 2018b:9:161-8.
Saha S, Schramm P, Nolan A, Hess J. Adverse weather conditions and fatal motor vehicle crashes in the United States, 1994-2012. Environ Health. 2016;15(1):104.

Sánchez-Mangas R, García-Ferrrer A, De Juan A, Arroyo AM. The probability of death in road traffic accidents. How important is a quick medical response? Accid Anal Prev. 2010;42(4):1048-56. https://doi.org/10.1016/j.aap.2009.12.012.

Shinar E. Safety and mobility of vulnerable road users: pedestrians, bicyclists, and motorcyclists. Accid Anal Prev. 2012;44(1):1-2. https://doi.org/10.1016/j.aap.2 010.12.031.

Smith TT, Zaitchik BF, Gohlke JM. Heat waves in the United States: definitions, patterns and trends. Clim Chang. 2013;118(3):811-25. https://doi.org/10.1007/ s10584-012-0659-2.

Theofilatos A, Yannis $\mathrm{G}$. A review of the effect of traffic and weather characteristics on road safety. Accident Analysis Prev. 2014a;72:244-56.

Theofilatos A, Yannis G. A review of the effect of traffic and weather characteristics on road safety. Accid Anal Prev. 2014b;72:244-56. https://doi. org/10.1016/j.aap.2014.06.017.

U.S. Global Change Research Program. Impacts, Risks, and Adaptation in the United States: Fourth National Climate Assessment, Volume II. U.S. Global Change Research Program: Washington, DC; 2018.

Wang Y. Smoothing spline models with correlated random errors. J Am Stat Assoc. 1998;93(441):341-8. https://doi.org/10.1080/01621459.1998.10474115.

Wang Y, Zhang W. Analysis of roadway and environmental factors affecting traffic crash severities. Transport Res Procedia. 2017;25:2119-25. https://doi. org/10.1016/j.trpro.2017.05.407.

Williams AA, Allen JG, Catalano PJ, Buonocore JJ, Spengler JD. The influence of heat on daily police, medical, and fire dispatches in Boston, Massachusetts: relative risk and time-series analyses. Am J Public Health. 2020;110(5):662-8. https://doi.org/10.2105/AJPH.2019.305563.

World Health Organization. Sustainable Development Goal 3: Ensure healthy lives and promote well-being for all at all ages. 2015 https://sustaina bledevelopment.un.org/ sdg3 (accessed 21 Oct 2020).

Wu CYH, Zaitchik BF, Gohlke JM. Heat waves and fatal traffic crashes in the continental United States. Accid Anal Prev. 2018;119:195-201. https://doi. org/10.1016/j.aap.2018.07.025.

Xing $F$, et al. Hourly associations between weather factors and traffic crashes: non-linear and lag effects. Analytic Methods Accident Res. 2019;24:100109.

Zhai X, Huang H, Sze NN, Song Z, Hon KK. Diagnostic analysis of the effects of weather condition on pedestrian crash severity. Accid Anal Prev. 2019;122: 318-24. https://doi.org/10.1016/j.aap.2018.10.017.

Zhan Z-Y, Yu Y-M, Chen T-T, Xu L-J, Ou C-Q. Effects of hourly precipitation and temperature on road traffic casualties in Shenzhen, China (2010-2016): a time-stratified case-crossover study. Sci Total Environ. 2020;720:137482. https://doi.org/10.1016/j.scitotenv.2020.137482.

\section{Publisher's Note}

Springer Nature remains neutral with regard to jurisdictional claims in published maps and institutional affiliations.

Ready to submit your research? Choose BMC and benefit from

- fast, convenient online submission

- thorough peer review by experienced researchers in your field

- rapid publication on acceptance

- support for research data, including large and complex data types

- gold Open Access which fosters wider collaboration and increased citations

- maximum visibility for your research: over $100 \mathrm{M}$ website views per year

At $\mathrm{BMC}$, research is always in progress.

Learn more biomedcentral.com/submissions 